\section{HACIA LA DEFINICIÓN DE UN NUEVO LIBERALISMO. EL PENSAMIENTO TARDÍO DE ORTEGA Y GASSET}

\author{
José Luis Villacañas Berlanga \\ Universidad Complutense de Madrid
}

\section{TOWARDS THE DEFINITION OF A NEW LIBERALISM: THE LATE THOUGHT OF ORTEGA Y GASSET}

\begin{abstract}
This essay shows the theoretical Ortega's inability to understand Tocqueville's thinking. This inability was established by a number of positions/ideas and prejudices about the destiny of the American way of life, by a wrong active euro-centrism and a badly understood liberalism. The main consequence was undoubtedly the impossibility of assuming the main Tocqueville's thesis: the democracy as a destiny. The sudden interruption of the reading of the French author, back to the Spanish exile became a symptom of the bankrupt of a philosophical thinking.
\end{abstract}

KEY WORDS: Liberalism; democracy; euro-centrism; colonies; America; pro-Franco doctrine. Ortega y Gasset.

1. La modulación del pensamiento liberal. La reflexión orteguiana sobre el liberalismo parece constitutiva de su pensamiento. Ortega nació con ella, y de ella brotó su vieja andanada crítica contra el sistema de la Restauración, corrupto e incapaz'. A este tiempo se ha llamado su primera etapa liberal, organizada alrededor de "La pedagogía social del liberalismo". Pedro Cerezo, que se ha ocupado de sistematizar la relación de Ortega con el liberalismo, define esta época como aquella en la que se pretende un equilibrio entre el individuo y la sociedad, propio del viejo socialismo liberal de la tradición kantiana de H. Natorp y de Berstein. Liberalismo aquí se definía por la idea moral que sitúa toda la estructura social en función del fin final del ser humano, ese momento que subraya la específica diversidad de las realizaciones personales de la cultura. La sociedad y su organización cultural, por tanto, aparecen como la mediación adecuada al fin moral que hace del ser humano el único portador de la dignidad. Entre la sociedad y el ser humano se tejen así convergencias basadas en una universalidad normativa. De ahi que las mediaciones pasen por la defensa de la democracia. El texto perfecto para esta época dice asi: "Socialización de la cultura, comunidad del trabajo,
RESUMEN: Este ensayo muestra la incapacidad teórica de Ortega para hacerse con el pensamiento de Tocqueville. Esta incapacidad estaba determinada por una serie de posiciones y prejuicios sobre el destino de la vida americana, por un eurocentrismo militante inadecuado y por un liberalismo mal entendido. La consecuencia desde luego fue la imposibilidad de asumir la tesis principal de Tocqueville, la democracia como destino. La interrupción abrupta de la lectura del autor francés, al regreso del exilio español, se convirtió así en un sintoma de la bancarrota de un pensamiento.

PALABRAS CLAVE: Liberalismo; democracia; eurocentrismo; colonias; América; franquismo. Ortega y Gasset.

resurrección de la moral: esto significa para mí la democracia" 2 . Era el período en que la cultura portaba fuerzas emancipadoras.

No creo que la gran etapa de actividad política que se inicia en 1914 sea diferente de la juvenil anterior, por mucho que el acento se ponga en la emoción vital específica que, como condición, permite otorgar al futuro más valor que al pasado3. Aquí, en Vieja y nueva política, liberalismo es sobre todo espíritu de cambio, incluso de revolución, y por eso implica un tono vital. Es verdad que Ortega comprende la imposibilidad de confiar en el Estado español, y por eso se ve obligado a limitar la dimensión socialista de su visión juvenil anterior, forjada en pensadores que confiaban en un Estado fuerte como por aquel entonces parecía la Alemania del II Reich. Frente a ello, Ortega confía y decide trabajar desde una comprensión de la nación, como lugar donde anidan las fuerzas vitales emancipatorias. Por eso se puede hablar de un liberalismo nacional y esa visión de las cosas ofrecía el medio para realizar las dimensiones sociales e individuales en equilibrio, siempre bajo la estructura teórica de la teoría de la cultura y la aspiración moral de una vida auténtica. 
Estas dimensiones del pensamiento de Ortega presentan poca dificultad ${ }^{4}$. Ofrecen respuesta a realidades agotadas y a menudo en Ortega se presiente el tono desesperado de batallar con el agua hasta la garganta ${ }^{5}$. De una forma $u$ otra, con matices más liberales o más autoritarios, en lucha contra la Restauración y la Dictadura o en la búsqueda de la rectificación de la República, Ortega se mantuvo fiel a todas ellas. Lo problemático comienza con la actitud final de Ortega hacia el liberalismo. Pues solo entonces, y en concreto a partir de El tema de nuestro tiempo ${ }^{6}$, el pensamiento de nuestro autor se pone en relación con procesos mundiales y con realidades sin definir, esas en las que el pensamiento tiene que ser al mismo tiempo un poco profético. Y en cierto modo, como en el caso de Max Weber, situado ante procesos modernos cuyo montante trágico se respiraba por doquier, Ortega se sintió excitado hasta el extremo de hablar del filósofo como un aliado del espíritu profético de anticipación. Lo hizo en el escrito que, a mi modo de ver, acabó por determinar su posición ante la II.a República española, y el que puso las bases de su visión final sobre el liberalismo. Me refiero a La Rebelión de las masas y a los textos complementarios, propios de la época en los que formulaba su teoría de la razón vital y su paso a la razón histórica. Por eso, creo que nuestra mirada se debe centrar aquí, pues de aquí brota su interpretación de la política española y su decepción respecto a ella, tanto como sus impresiones sobre Benjamin Constant y el nuevo liberalismo ${ }^{7}$.

2. Los nuevos trascendentales: Europa y el hombre masa. La época del pensamiento de Ortega que surge a finales de los años 20, orientada hacia la configuración de la razón vital ${ }^{8}$, está marcada por el concepto trascendental de hombre masa. Este concepto estructura los materiales de Ortega y le ofrecen su orden. Entre ellos, debemos situar el problema del liberalismo. En cierto modo, el asunto del hombre masa, que había alcanzado su formulación filosófica plena en el concepto de man de Martin Heidegger, pero que presionaba hacia el aristocratismo compensatorio ya desde Nietzsche, mantenía una compleja relación con el pensamiento de la nación. Desde cierto punto de vista, la nación política producía masa. Ese era el objeto de todo gobierno nacional, la forja de una extrema homogeneidad. Ahora Ortega veía clara la consecuencia y le parecía sencillamente pavorosa ${ }^{9}$. España no era diferente en esto. Pensar Europa era sencillamente tout court pensar España. El destino ya era compartido. Ahora se podía hablar desde la gran filosofía sobre España sin hacer comentarios al margen. No podemos negar que Nietzsche está presente en La rebelión de las masas. Cuando Ortega presentó sus tesis a los franceses, en 1937, lo quiso dejar claro y, con una continua ironía, dijo que su libro, en el caso de que lo fuera, trataba de un asunto "demasiado humano". Luego habló de la aceleración del tiempo, del presente que ya es pasado y dejó caer el tema splengeriano de la decadencia ${ }^{10}$.

En la presentación de su tema a Europa, Ortega confesaba que su obra estaba tejida de una soledad radical, en la que él había peleado una y otra vez con los límites de la comunicación y del lenguaje. Si el lenguaje es diálogo, vino a decir, en España resultaba imposible escapar al continuo malentendido del monólogo. El lenguaje estaba atravesado por el imperativo de lo concreto y esta dimensión ya era definitiva para él. De ella se derivaba su tarea, su función, su especificidad liberal. Por ello pudo hablar de una afinidad electiva entre Europa y el liberalismo". De hecho, en este espacio se abre siempre su horizonte. La sociedad europea, junto con todas las estructuras que se derivan de la realidad social, no había sido jamás homogénea. Un fuerte principio de refracción imponía a cada norma universal su diversificación europea ${ }^{12}$. Iglesia e iglesias, imperium y Estados, razón y estilos nacionales, belleza y gustos, cualquier principio espiritual siempre se concretaba en sus variaciones nacionales. Esta constitución había garantizado que Europa siguiera siendo un espacio social respirable. Europa tenía de todo, usos, costumbres, opinión pública, derecho y poder, pero siempre alentando formas diversas. Esas formas eran las naciones. No las naciones políticas, esas que imponían un poder directo y homogeneizador, sino las sociedades culturales propias que garantizaban la diversidad hermenéutica de los principios universales.

Europa era a los ojos de Ortega -como lo había sido para Fichte- una sociedad. Por eso era altamente probable un Estado común europeo. Si el concepto de masa es la condición estructural del pensamiento de Ortega de esta época, el de Estado europeo es el horizonte en el que sus análisis confluyen como una meta. Sin este juego de un concepto sociológico -el de masa- dentro de un escenario geoestratégico ${ }^{13}$-el de Estado europeo-, no se entiende el contexto en el que juega el concepto de liberalismo de Ortega. En 1937, y en los meses siguientes, se necesitaba mucha fe para afirmar con fuerza que Europa era 
una sociedad. Al menos en el "Prólogo para franceses" así se lo parecía a Ortega y por eso citaba con frescura a Montesquieu o Balzac ${ }^{14}$. Todo lo que se debía pensar era la figura de ese Estado supranacional. Desde luego, sería una integración de la "pluralidad de las formas vitales"15. Lo que estaba sucediendo en España tenía que ver con eso, y muy pocas veces los estudiosos han percibido que sólo desde esta óptica de la guerra civil se divisa lo que Ortega contempla. Ante sus ojos, era una fantasía imaginar a España o Alemania, Francia o Italia como realidades sustantivas e independientes ${ }^{16}$. Ahora bien, la cuestión es que el viejo sistema de equilibrio de poderes europeos - tan alabado por Ranke ${ }^{17}$ - no podía operar por más tiempo de forma espontánea. Esto era así porque la opinión pública europea se había desarticulado.

Este fenómeno tenía que ver con la noción de masa. Hasta ahora, la homogeneidad europea se había refractado en diversidades y en el seno de cada nación una elite específica permitía la emergencia de una forma dada de la opinión pública cosmopolita. Sin embargo, cuando la homogeneidad europea era la masa, esta se refractaba en cada país también mediante una masa nacional. Ahora bien, esta figura impedía todo aliento cosmopolita y troceaba la opinión pública europea, de tal manera que nadie podía ejercer su poder unificador. El juego perturbador del hombre masa, desde este punto de vista, le parecía a Ortega muy grave. Por una parte, el hombre masa rompía con lo propio del estilo nacional de vida, eliminaba las aristocracias formadas en él y, así, vivía de espaldas a su pasado, sin historia ${ }^{18}$. Sin embargo, esta res nullius de la masa, ajena al viejo espíritu de homogeneidad nacional, ofrecía la ancha puerta por la que entraba el universalismo abstracto, propio del espíritu revolucionario. Ortega interpretaba asi la fase comunista de la revolución española. La otra manifestación positiva de este nuevo hombre era la especialización científica, carente por completo de todo elemento cultural, algo que Ortega había analizado de forma pormenorizada en su Misión de la Universidad ${ }^{19}$, un escrito de los mismos años que La rebelión de las masas. Así que la ruina del estilo nacional de vida implicaba la ruina del cosmopolitismo -la manera en que se hacía valer la opinión pública europea-. Ahora sólo quedaba en pie el internacionalismo que homogeneizada sin diferenciar, y que era la metafísica abstracta del obrero actuaro. Esto y ese escuálido principio de la especialización científica.
En este doble juego de masa y universalismo abstracto, por un lado, y especialización técnica por otro, el liberalismo era inviable. En realidad, la actualidad se dirigía hacia una situación que parecía la del Bajo Imperio Romano ${ }^{21}$. Pues liberalismo era el principio de refracción, de diferencia, de heterogeneidad respecto del espíritu universal europeo, la piedra en la que se fundaban las diferencias nacionales. $Y$ lo era tanto y en la medida en que, en cada nación, impulsaba también el espíritu de diferencia, de diversidad en los tipos humanos. Esa era la piedra de toque por la que cada nación reconocía su aristocracia. Ahí se resumía la historia de Europa. Citando a Guizot, su Histoire de la Civilisation en Europa, que prologaría, afirmó que "libertad y pluralismo son dos cosas reciprocas y ambas constituyen la permanente entraña de Europa"22. Tras la masa y el universalismo revolucionario, tras el espíritu limitado del científico especialista e inculto, el liberalismo sólo podía ser algo nuevo, reconquistado. Entonces fue consciente Ortega de que su vieja doctrina del liberalismo ya no servía. Su pensamiento dio un impulso más allá y, como era de esperar, acompañó sus propias reflexiones filosóficas generales ${ }^{23}$.

3. La muerte del viejo liberalismo. Fue entonces cuando Francia se convirtió en el punto de referencia de los análisis de Ortega. En realidad, nuestro pensador aludía a la sociología francesa, que le parecía "la reciente tradición francesa, superior en este orden de temas a las demás"24. Para ello, sin embargo, tenía que disciplinar sus adhesiones a lo francés. Pues en Francia estaba lo mejor, esa mirada sociológica que podía fundar el nuevo liberalismo, pero también lo peor, el espíritu revolucionario, la verdadera clave de la política homogeneizadora, abstracta, unilateral y universalista, siempre de valor absoluto. Ese espíritu había surgido hacia 1750, con la extravagante idea de la razón como motor de la igual constitución política de los pueblos $^{25}$. En realidad, estos "intelectuales descarriados ignorantes de sus propios límites" 26 habían matado el viejo liberalismo anclado en el individuo ${ }^{27}$. El verdadero liberalismo venía de Francia, pero también venía de ella justo lo que más lo amenazaba, la homogeneidad colectivizadora, que Ortega veía a la vez en la Revolución Francesa y en la contrarrevolución conservadora de Bonald y de De Maistre, que no eran lo contrario de la revolución, sino una revolución contraria. Socialismo es Francia, desde Robespierre y Saint-Simon, pero también desde Bonald y Comte. En suma, el futuro estaba en comprender el combate francés entre el triunfante universalismo de la política absoluta

ARBOR Vol. 187750 julio-agosto [2011] 741-754 ISSN: 0210-1963

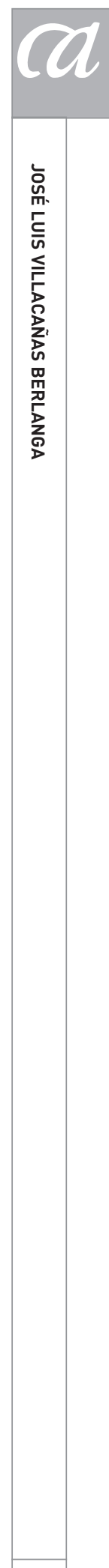

743 
de 1789 y un liberalismo que desde aquella misma fecha pugnaba por dotarse de concepto.

El siglo XIX, en un diagnóstico que se remonta a Simmel, había descubierto lo colectivo y había arrinconado el liberalismo individualista. No era de lamentar. Este era unilateral y en esa misma medida falso. Ahora convenía ejercer los derechos de la inteligencia y reconocer que en ese principio del colectivismo anidaba un monstruo: el universalismo internacionalista de las masas que eliminaba de forma revolucionaria la estructura societaria liberal europea. De esa mirada debía surgir un liberalismo "de estilo radicalmente nuevo"28, pero capaz de conectar con los viejos resistentes. Ortega aclaraba que tal luz germinaba en la línea del horizonte. Si reclamó capacidades anticipatorias y proféticas ${ }^{29}$, fue sobre todo porque deseaba ver claro en este asunto. Sin embargo, había sido precedido por algunos otros. Sin contar a Montesquieu, al menos había que nombrar a Tocqueville, a Macaulay, a Stuart Mill. De hecho, este no hacía sino comentar un pasaje de Humboldt. $Y$ este, ya lo sabemos, se había formado en contacto con el joven Constant en el Paris de 1793. Así, de forma un tanto precipitada, intuitiva, Ortega llega a una posición estable: enlazar a los doctrinarios, a los resistentes frente a la Revolución Francesa, con la posibilidad de un nuevo liberalismo.

En el fondo, poco a poco, Ortega llegó a la comprensión de que la misma batalla que se daba en el presente ya se habia dado entre la Revolución francesa y los liberales doctrinarios. En aquella hora habia irrumpido la política total, lo que Ortega Ilama "el politicismo integral", con su pretensión de hacer de la política la esfera de acción social absolutamente valiosa. Este fenómeno, que ocurre por primera vez con la Revolución Francesa, "es una y la misma cosa con el fenómeno de la rebelión de las masas" $^{\prime 30}$. La política, elevada a esfera absoluta, implicaba la intromisión ingente de la propaganda en la personalidad, la construcción de la subjetividad desde el poder, la ruina del ensimismamiento propio de la tarea formadora de la subjetividad en favor del ruido de los demagogos ${ }^{31}$. Así se comenzó a trazar en Europa el camino real hacia la plena socialización del ser humano y su anulación como persona. El ser humano dejó de ser una "figura individual" que brotase de una "imagen de su fantasía" y se hundió en esa masa parisina informe. Con ello, Europa comenzó a dar pasos hacia su transformación en una termitera ${ }^{32}$. Alli, en 1793, se enfrentaron por primera vez los irresponsables demagogos con los profundos intelectuales del presente; con los ancestros de Ortega, los liberales doctrinarios.

Desde entonces, desde 1750, según asegura Ortega, opera la idea de que la revolución general política absoluta es un método de resolver problemas ${ }^{33}$. Sea cual sea el contenido de la política, proceda de derechas o de izquierdas, esta se ha hecho absoluta y adopta el método revolucionario. $Y$ este método implica una corrupción intelectual del lenguaje, que de ser diálogo, pasa a ser imposición universal dogmática; y de ser algo concreto se convirtió en discurso abstracto. Ese método se ha impuesto de modo tan universal como su propio soporte humano, el hombre masa. Con ello se ha desplazado de la dirección intelectual a los hombres responsables de su tarea, y se ha elevado hasta la cima a los elementos degenerados, estranguladores de civilizaciones ${ }^{34}$. Por ello, una nueva definición del poder responsable de las ideas, un nuevo liberalismo, una nueva reivindicación de la diversidad nacional y un nuevo pensamiento sobre Europa -la "reconstitución de Europa"35-, todas estas eran cosas que caminaban juntas en el pensamiento de Ortega. Sólo este conjunto sistemático de operaciones intelectuales podría detener la metodología revolucionaria, el universalismo internacionalista, el hombre masa y su figura, el demagogo irresponsable. Sin duda, el punto de cruz pasaba por aclararse sobre la verdadera ontología de Europa. Se trataba de saber si era una sociedad, si albergaba un principio universal, y si por tanto podia emerger de ella un derecho y un poder público; o bien si era meramente una pluralidad de naciones y entonces nada podía hacer frente al universalismo descarnado y abstracto del hombre masa y de la revolución.

La posición de Ortega en el "Epilogo para ingleses", escrito en 1938, era mucho más pesimista que en el "Prólogo para franceses", escrito unos meses antes. "Si Europa es sólo una pluralidad de naciones, pueden los pacíficos despedirse radicalmente de sus esperanzas", dijo entonces ${ }^{36}$. Puesto que el escrito es claramente belicista, Ortega parece sugerir que Europa ya se ha convertido en un mero conglomerado de naciones, que nada une a los europeos mediante un vínculo universal espiritual, ni mediante minorías responsables, ni a través de convicciones comunes. El trascendental "sociedad Europea" que ha dado sentido a la diversidad de las naciones europeas, ese credo intelectual y moral de Europa ${ }^{37}$, le parecía roto y quebrado. 
La conclusión prevé como seguro el triunfo de las masas. 0 el de su complemento, el poder espiritual salvaje de las figuras bárbaras de especialistas científicos que se atreven a hablar de todo, como si fueran portadores de cultura, como ese Einstein, que se lanza a juzgar el proceso histórico español ${ }^{38}$. Europa, dice Ortega, se ha des-socializado. Por mucho que las masas constituyan una forma universal de existencia, el primer efecto que han producido ha sido eliminar la forma social europea, con sus valores y poderes espirituales responsables, y dejar a la deriva las formas nacionales. Las formas vitales nacionales basadas en el hombre masa ya no son tales, no existen. Implican también violencia interna contra la propia historia, contra los poderes intelectuales representantes del viejo estilo nacional. Por eso, ya no hay nada por encima de los diversos pueblos, y por eso "la pura verdad es que, desde hace años, Europa se halla en estado de guerra, en el estado de guerra más radical de todo su pasado" 39 . Ese ha sido el efecto de la propaganda de los nuevos medios de comunicación, que a través de la prensa ha sustituido a la Universidad como exclusivo poder espiritual sobre la gente ${ }^{40}$. Se trata, en suma, de un estado de guerra entre sus naciones y de un estado de guerra civil interno a sus naciones. En suma, el escenario de Carl Schmitt: una política dominada por el enemigo interior y exterior. España era el primer episodio de esa guerra civil interna. Pronto vendría el segundo episodio de una lucha de naciones.

Debemos reparar en este doble frente de la guerra. Aquí la matriz de la Revolución francesa se impone de nuevo: guerra civil y guerra continental, lucha contra todo lo que representa diversidad en el seno de una nación y lucha contra lo inaceptable y hostil de otro principio nacional diferente del propio. Europa era un pensamiento que unía las naciones europeas tanto como organizaba sus elites. Ahora el principio de la elite ha estallado generando ese doble frente. "Ahora se ve cómo la cohesión interna de cada nación se nutría en buena parte de las vigencias colectivas europeas", dice Ortega concluyendo su argumento ${ }^{41}$. Esta falta de cohesión comunitaria - "esta debilitación simultánea de la comunidad entre los pueblos de occidente"42 - ha emergido tan pronto se abrió paso el "uso de convertirse unos pueblos en jueces de los otros, de despreciarse y denostarse porque son diferentes" ${ }^{43}$. Esta ha sido la hazaña de la prensa, que acerca unas naciones a otras, pero sólo en lo negativo ${ }^{44}$. La escisión entre lo nuevo revolucionario y lo tradicional recorre las naciones y Europa entera ${ }^{45}$. La diferencia reacción-revolución que había producido 1789 se había generalizado. Sólo recomponer Europa, reorganizar la diversidad nacional desde la primacía de un espíritu común, generar nuevos poderes intelectuales responsables, vertebrar elites, sólo este proceso podría impedir el desnudo encuentro de naciones contra naciones y de nacionales contra nacionales. Sólo el nuevo liberalismo podría lograr todo esto. Mientras no fuera así, el hecho desnudo de la doble guerra se impondría.

\section{El futuro y el pasado. Ortega no pensaba que esa nueva} generación de Europa pudiera lograrse al margen de una nueva oportunidad para la Universidad. En cierto modo, su dilema decía así: o propaganda abstracta, internacionalista, dominio de la prensa, especialización y barbarie; o liberalismo de nuevo cuño, capaz de ser a la vez nacional y europeo, dotado de una cultura poderosa y de organizarse desde una recomposición de la misión de la Universidad. Y así leemos este pasaje: "Es pues cuestión de vida o muerte para Europa rectificar tan ridícula situación [de dominio de la prensa]. Para ello tiene la Universidad que intervenir en la actualidad como tal Universidad, tratando los grandes temas del día desde su punto de vista propio -cultural, profesional o científico-. De este modo [...] metida en medio de la vida, de sus urgencias, de sus pasiones, ha de imponerse como un 'poder espiritual' superior a la Prensa. [...]. Entonces volverá a ser la Universidad lo que fue en su hora mejor: un principio promotor de la historia europea"46. Pero desde cierto punto de vista esta propuesta, que encerraba dimensiones normativas muy rigurosas, quedaba en al aire de las reformas por venir y no se articulaba bien con su propuesta de un nuevo liberalismo ${ }^{47}$.

Cuando, para resolver la doble guerra civil, Ortega reclamaba una "nueva técnica de trato entre los pueblos", cuando exigía una nueva técnica política, cuando avistaba un nuevo liberalismo, en el fondo todo ello se concretaba en una nueva sociedad europea capaz de fundar un poder público europeo. Como sabemos, en la idea de Ortega, Europa sería una ultra-nación y esto exigía recomponer el sentido nacional de las partes y su doble juego de universalidad y particularidad. Sin embargo, en esa guerra civil no parecía abrirse otra posibilidad que la de una violencia desnuda entre las partes. Esta era la previsión de Ortega $y_{1}$ en cierto modo, si de algo acusaba a Inglaterra en el "Epílogo" era de su pacifismo, que le impedía prepararse para el futuro. Esa guerra, y no la Universidad, le parecía

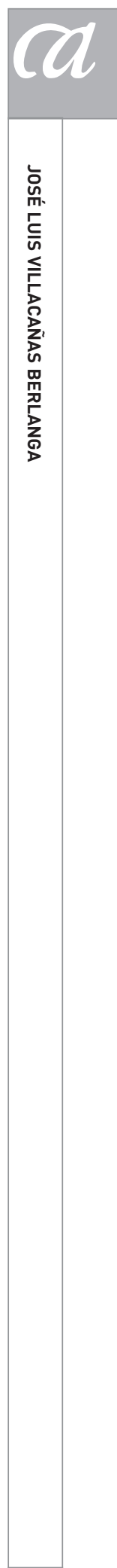

745 
el fontanal desde donde podía brotar la nueva sociedad, y con ella el nuevo derecho. Los derechos de las naciones, en un momento de odio entre ellas, serían recíprocamente desconocidos por todas $y$, por lo tanto, sólo una nueva sociedad europea podría forjar un nuevo derecho internacional. Ante este futuro, como un obstáculo poderoso, se alzaban Versalles y Ginebra, en la línea de lo que pensaba Carl Schmitt. En la misma línea que habría de desarrollar Kelsen un poco más tarde, Ortega sugeria que era preciso forjar un derecho internacional europeo "sin el Estado y su actividad estatuaria"48. En realidad, la ultra-nación que habría de ser Europa no le parecía a Ortega que tuviera que renunciar al principio de soberanía de los Estados como árbitro último del derecho internacional. Sin embargo, tal sentido tendría que ser limitado. Pero una guerra debía mediar, pues una nueva sociedad europea debía surgir de ella, y sólo sobre esta novedad podría producirse de forma espontánea el derecho $0^{49}$. No cabe duda: para Ortega esa guerra y su mediación implicaba previamente "una etapa de nacionalismos exacerbados". Sólo así se podía contrarrestar el "descarrío metódico que representa el internacionalismo" ${ }^{50}$. La meta, sin embargo, era la "unidad concreta y llena de Europa". "Las naciones europeas llegan ahora a sus propios topes y el topetazo será la nueva integración de Europa".

Y aqui es donde Ortega conectaba de forma productiva la situación del presente con la emergencia del nuevo liberalismo. Pues entonces, tras recordar el estado de guerra radical de Europa, dijo: "Es frívolo interpretar los regímenes autoritarios del día como engendrados por el capricho o la intriga" ${ }^{11}$. En cierto modo, formaban parte de la estructura de la mediación. Aunque Ortega no da nombres, en diciembre de 1937 esto quería decir mucho. Para Ortega eran "manifestaciones ineludibles del estado de guerra civil en que casi todos los paises se hallan hoy". En realidad, para disminuir el estado de guerra, se tenía que recomponer una voluntad de no injerencia en los asuntos de los demás. Tal cosa, con la estructura de la opinión pública mundial y europea, resultaba imposible. Pero como nadie dispone de la "verdad de lo vivido", y las opiniones públicas intervienen desde el veneno de la prensa, era necesario el error, la ofensa, la diferencia que crece y se envenena. Desde luego, Ortega reclamaba con ello comprensión para los regímenes autoritarios. Los que no tenían acerca de ellos "la verdad de lo vivido", estos debían callar ${ }^{52}$. La frase recomendaba silencio sobre la guerra civil española. De otra manera no se entiende este pasaje: "Sostengo que la injerencia de la opinión pública de unos paises en la vida de los otros es hoy un factor impertinente, venenoso y generador de pasiones bélicas, porque esa opinión no está aún regida por una técnica adecuada al cambio de distancia entre los pueblos. Tendrá el inglés o el americano todo el derecho que quiera a opinar sobre lo que ha pasado y debe pasar en España, pero ese derecho es una injuria si no acepta una obligación correspondiente: la de estar bien informado sobre la realidad de la guerra civil española, cuyo primero y más sustancial capítulo es su origen, las causas que la han producido"53. Lo que Ortega quería decir lo dejó claro en este otro pasaje: "Mientras en Madrid los comunistas y sus afines obligaban, bajo las más graves amenazas, a escritores y profesores a firmar manifiestos, a hablar por radio, etcétera, cómodamente sentados en sus despachos o en sus clubs, exentos de toda presión, algunos de los principales escritores ingleses firmaban otro manifiesto donde se garantizaba que esos comunistas y sus afines eran los defensores de la libertad"54.

Desde luego, Ortega no llegó a decir esto mismo de Hitler y sabía de lo que hablaba respecto a Madrid porque lo habia vivido. En todo caso, y lejos de ir más allá en el análisis del específico lugar de la II República en el mundo ${ }^{55}$, veía claro que nadie podía aludir a la falta de información sobre la situación española. De eso se encargaba la prensa mundial. Ortega, instalado en lo que llamaba una "moderación" lentamente construida ${ }^{56}$, se cansaba de recordar que los corresponsales eran partidistas y maldecía a la "fauna periodística" e insistía acerca de la necesidad de la refor$\mathrm{ma}^{57}$. Todos ellos no lograban sino propalar información sin conocer "lo más auténticamente real de la realidad". Así que la prensa ofrecía mero desconocimiento, ignorante de su propia ignorancia ${ }^{58}$. En estas condiciones era inútil la relación entre pueblos y cualquier contacto no cesaba de producir malestar y odio. La previsión de Ortega, muy sutilmente expuesta, sugiere no obstante que finalmente "la nación acaba por estabilizarse en su verdad". En ella habrian de converger los partidos tras la guerra civil. $Y$ entonces se unirán en su verdad viviente, en su intimidad, en su sistema de secretos. Los avisos de Ortega acerca de la naturaleza no mística de sus expresiones no son convincentes, desde luego, pero sí lo era su previsión implícita de que a primeros de 1938 veía ya descontada la guerra civil en España. El estado de guerra civil en España ya se había superado. España le parecía casi lista para la nueva 
empresa europea. En realidad, era el primer país preparado para ella.

Entonces Ortega dejó caer su previsión y mostró dónde quería situarse, desde luego. Pues dijo que en esta situación de guerra civil europea "pronto vendrá una articulación de Europa en dos formas de vida pública: la forma de un nuevo liberalismo y la forma que, con un nombre impropio, se suele Ilamar totalitaria"59. La cautela de Ortega causa estupor. Sin embargo, deja el comentario en la más extraña abstracción. No sabemos por qué es impropia la caracterización de totalitarismo. Pero sea como sea, no cabe duda de que Ortega deseaba alinearse con el nuevo liberalismo. El enfrentamiento entre ambas formas de entender las cosas no podría obviarse. Pero tampoco su reciproca necesidad. "Toda forma de vida ha menester de su antagonista", aseguró. La ingenuidad de Ortega resulta perceptible y su capacidad para analizar la situación mundial parece mejorable. A pesar de todo no debemos ejercer la superioridad de quien mira setenta años después. Nos interesa más profundizar en su carácter sintomático, pues desvela profundos rasgos de su filosofía.

La tesis de Ortega era sencillamente que "el totalitarismo salvará al liberalismo". Esta posición es inicialmente comprensible: los enemigos se refuerzan entre sí y el peligro que representa el totalitarismo producirá energías para salvar la libertad en Europa. Sin embargo, descubrimos pronto que el análisis de Ortega no consiste en proponer la inevitable creciente liberal para hacer frente al peligro totalitario. No es esto. Lo que Ortega quiere decir es que totalitarismo - de ahí la impropiedad de la expresión-y liberalismo están llamados a entenderse, a cooperar. La frase entera dice asi: "El totalitarismo salvará al liberalismo, destiñendo sobre él, depurándolo, y gracias a ello veremos pronto a un nuevo liberalismo templar los regímenes autoritarios". Este es el punto: el totalitarismo tras la victoria será meramente autoritarismo y este no será incompatible con el liberalismo. Ya lo sabía Hobbes. Ambos principios están condenados a entenderse en un autoritarismo templado y liberal. De hecho, la previsión de España, de esa España que recuperaba su intimidad y verdad tras la guerra civil, consistía en que estaba en muy buenas condiciones para iniciar ese camino de síntesis. Con la sutileza de quien sabe colocar la frase en el momento oportuno, Ortega nos informa de que "Los pueblos menores adoptarán figuras de transición e intermediarias.
Esto salvará a Europa". España, un pueblo menor, pronto entraría en el camino de una figura intermedia entre autoritarismo y liberalismo. Sin duda, se trataría de un "equilibrio mecánico y provisional", pero al menos permitirá una "nueva etapa de mínimo reposo". Por mínimo que fuera, le parecía a Ortega suficiente para que brotara "en el fondo del bosque que tienen las almas, el hontanar de una nueva fe". Para ello se necesitaba el ensimismamiento que incluso los más pesimistas sabían que iba a ser el destino de España. Esa nueva fe común de Europa, era exactamente la de los liberales nuevos.

5. Doctrinarismo. Para el Ortega posterior a 1936, si el futuro pasaba por un autoritarismo templado por liberalismo, por ese sincretismo en que se salvaba Europa, entonces se entiende bien que el modelo fuera el liberalismo de los doctrinarios franceses. Desde cierto punto de vista ellos habían sabido detener la guerra civil, configurar un directorio, mantener un sentido para las libertades subjetivas, fundar una libertad de los modernos, frente a la libertad de los antiguos y abrir el paso a un régimen de autoridad. Pero cuando efectivamente vamos a las obras de Ortega para ver el análisis del liberalismo doctrinario, nos damos cuenta de su escualidez. Aquello sobre lo que había puesto las esperanzas de futuro en el año 1937 y 1938, apenas mereció un análisis pormenorizado. Cuando recorremos el Índice de autores y conceptos de la obra de José Ortega y Gasset, vemos que Benjamin Constant aparece en toda su obra en tres páginas. Una de ellas es de 1916 y analiza el Adolfo, en el que Ortega pondera la relevancia del amor para la filosofía ${ }^{60}$. La otra es de 1917 y desarrolla la anterior ${ }^{61}$. Como autor político y padre de los doctrinarios sólo aparece en el "Prólogo para franceses", para decir de él que es un retrasado del siglo anterior y que por eso no comparte el espíritu colectivista. Las ocurrencias y análisis sobre la obra de Guizot son igual de mínimas y formales ${ }^{62}$. Ortega afirma que "quien quiera de verdad ver claro qué es lo que pasa hoy en el mundo" necesita conocer la historia del siglo XIX y la centralidad de Francia. Pero en este prólogo deja caer lo verdaderamente innovador de los doctrinarios, y sobre todo del agudo Royer-Collard: construir una doctrina política en que "esta mezcla de principios -el derecho histórico de los reyes y el derecho ideal, racional, a priori del pueblovienen a cohabitación". Mediante esta síntesis de principios opuestos, ellos forjaron una doctrina y "dominaron intelectualmente los hechos". 
Como vemos, Ortega había identificado el paralelismo entre los doctrinarios y el nuevo liberalismo: la complexio de dos principios contrarios. En su caso, el principio monárquico y el derecho del pueblo. En el caso de Ortega, el del presente, el autoritarismo y el liberalismo. Lo mismo, aunque bajo la forma de lo diferente ${ }^{63}$. Pero en realidad, no mucho más. El agudo Royer-Collard comparece poco y nunca de forma pormenorizada ${ }^{64}$. Sin duda, con estas breves sugerencias, Ortega motivó el estudio de Luis Díez del Corral, El liberalismo doctrinario, editado en 1945, quien en una breve reflexión inicial reconocía la inspiración orteguiana ${ }^{65}$. No veremos nada más explícito que su análisis en "Prólogo para Franceses". Así que alli debemos marchar para recoger algún tipo de indicación ulterior. Sin embargo, Ortega no va mucho más allá y pronto redescubrimos la vieja idea: "Cuando Guizot, por ejemplo, contrapone la civilización europea a las demás haciendo notar que en ella no ha triunfado nunca en forma absoluta ningún principio, ninguna idea, ningún grupo o clase, y que a este se debe su crecimiento permanente y su carácter progresivo, no podemos menos de poner el oído atento"66. Ortega asiente: este hombre sabe lo que dice. Aunque su expresión sea negativa, produce en Ortega "visiones inmediatas". Con ellos se identifica, de eso no cabe duda, hasta en el gesto estético de distanciamiento, para "defenderse del abandono orgiástico en que vivía su contorno", algo que significaba mucho acerca de un tiempo del que la Zambrano recordaría como delirio. Lo que Guizot afirma viene del conocimiento profundo de la historia de Europa. Todo ello le permite decir a Ortega que el grupo de personas que de facto gobernó Francia hasta la revolución de 1848, le parece "lo más valioso que ha habido en la política". Su espíritu contra corriente y su política de resistencia sabia que tenían como aliado a la realidad, por ellos conocida como historia. De ahi su responsabilidad intelectual. Como es natural, su mejor sentido de la realidad les permitía disponer de una ética circunstancialista, tan afín a Ortega. "Los doctrinarios no tenían una doctrina idéntica, sino que variaba de uno en otro"67.

Lo más característico de este grupo consistía, a los ojos de Ortega, en que ante una situación dada, se movían con la flexibilidad propia de quien busca la meta final de la libertad. Respecto a esto, sabían que "las libertades públicas no eran otra cosa que resistencias". Sin duda, de esta manera interpretaban la división de poderes de Montesquieu, pero siempre desde una valoración superior de lo dinámico so- bre lo estático. Por eso, su virtud consistía en la flexibilidad. El estado de libertad no era sino un momento estático de un proceso dinámico de contrarresistencias de poderes y fuerzas, y entre estas las de dos órganos fudamentales, el individuo y el Estado, los representantes del liberalismo y del autoritarismo, que hacía del Estado representante de lo más pavoroso de lo colectivo ${ }^{68}$.

Lo decisivo de este planteamiento, sin embargo, residía en una capacidad de apreciar lo concreto de esas fuerzas mismas. Sin este elemento, todo se hundía. Y aquí hace pie uno de los momentos en que Ortega da un salto adelante en su filosofía y sobre la humilde proximidad de estos doctrinarios avanza en la construcción sistemática de su pensamiento. Pues Ortega reconoce que estos doctrinarios viven en el seno de la "mejor tradición racionalista". Son hijos de Descartes, desde luego, como siempre se vio Orte$\mathrm{ga}^{69}$. Sin embargo, en su búsqueda de principios absolutos, fundamentales, se han desviado del camino cartesiano del Yo, con su potencialidad de abstracción, y han dado con "lo histórico como el verdadero absoluto". Tras ellos se puede decir que "la historia es la realidad del hombre" y por eso, a partir de 1935, Ortega va a transformar su vieja razón vital en razón histórica. Y lo ha hecho al hilo de la necesidad de configurar un nuevo liberalismo y a la hora de leer la situación europea a la luz de los doctrinarios. Amantes de la historia, a los doctrinarios les parece absurdo negar el pasado, porque en el pasado está aquello que se puede llamar "natural del hombre". Que el ser humano no tiene naturaleza sino historia, esto es lo que ha descubierto Ortega en este punto. Por eso, el pasado era una de las fuerzas que había que integrar en una política de síntesis, si la libertad debía abrirse camino. En el pasado estaba la legitimidad y la condición de la libertad.

Como es fácil de comprender, este planteamiento le parecía a Ortega el propio de la vieja resistencia inglesa de Burke frente a la Revolución francesa y los doctrinarios eran sus discípulos franceses. Puesto que todo problema político es concreto, sólo se puede iluminar por la ciencia de lo concreto, la historia ${ }^{70}$. Con ello, toda la gran Europa aparecía dominada por una idea de historia natural de la libertad, por un crecimiento evolutivo de la misma que surgía desde el espiritu de las naciones. A fin de cuentas, el Volksgeist alemán no eran sino esprit des nations ${ }^{71}$. Por eso, el liberalismo era lo único apropiado a la nueva ontología que apuntaba tras la razón histórica: "La libertad ha significado 
siempre en Europa franquía para ser el que auténticamente somos"72. Que exista un ser que se expresa libremente en la historia, y no que es pura historia, es un detalle menor, aunque importante. Es lo que garantiza el suelo rocoso de la nación. Por eso, el principio del liberalismo era siempre nacional, en él anclaba "el perenne liberalismo europeo"73. Desde él se podría generar el verdadero futuro europeo, pero este pasaba por afirmar la propia historia en tanto historia nacional, los usos sociales concretos, los vínculos que ataban al hombre con la gente, los sistemas de creencias, aquello que garantizaba la diversidad de situaciones. Todo ello surgía ante la vista del filósofo justo de la mano de la "otra razón más radical que es la razón histórica", y que Ortega ya exponía en 1935 Historia como sistema, aunque todavía de forma inmadura ${ }^{74}$, aunque ya claramente anti-hegeliana. Su proximidad a estos textos sobre los doctrinarios y el problema del liberalismo queda clara cuando se cita a Comte y se dice: "Se puede asegurar hoy día que la doctrina que explique suficientemente el conjunto del pasado obtendrá inevitablemente, por esta prueba exclusiva, la presidencia mental del porvenir"75. Y esto era así porque Ortega reconocía que, en un ser histórico, el derecho fundamental era tener una historia, el "derecho de continuidad"76.

Vemos así que fue la ratio política lo que llevó a Ortega a proponer la razón histórica, ya con valor general para abordar los asuntos humanos ${ }^{77}$. Sin duda esto le permitía aproximarse de nuevo al viejo Nietszche, que había definido al ser humano superior como "el de más larga memoria". Como es natural, esto llevó a Ortega a otorgar relevancia a los símbolos de esa memoria y a esa continuidad histórica y así pudo valorar la centralidad de la monarquía como estructura simbólica de la continuidad de una nación. Inglaterra, una vez más, con su continua vinculación al pasado y con su comprensión del derecho como derecho histórico del antecedente, se elevaban a cierta clave modélica para Ortega ${ }^{78}$.

Sin embargo, en este mismo punto, Ortega revela la limitación de su propio planteamiento. Esa dimensión modélica de Inglaterra le impidió reconciliarse con los Estados Unidos. Para el hombre superior de la más larga memoria, Estados Unidos era puro primitivismo, una sociedad neocolonial. $Y$ esto además en mayor medida al norte que al sur ${ }^{79}$. Este punto, sostenido por los artículos sobre los Estados Unidos, escritos entre 1928 y $1932^{80}$, le impidió comprender la dimensión mundial de lo que se jugaba en Europa y las implicaciones de los Estados Unidos en este escenario. En este caso, el olvido fue letal. Porque le obligó a considerar la historia de los doctrinarios justo hasta 1848 y no más lejos. Esto, en alguien que cantaba la razón histórica, resulta más bien imperdonable, pues le impedía entender cómo habían evolucionado las fuerzas históricas concretas tras esa fecha y le impedía comprender los elementos en los que se debía fundar el nuevo equilibrio de la libertad y del Estado. Así consideró a los doctrinarios como la última palabra en la evolución histórica europea. En estas condiciones, concretar las posibilidades de su sentido del nuevo liberalismo, directamente apoyado en el arcaico ejemplo de los doctrinarios, eran mínimas. Tocqueville en este contexto quedaba fuera de consideración.

Tal cosa se ve en una ausencia de análisis muy sintomática y significativa. En efecto, en el Prólogo para franceses, de 1937, Ortega había dicho que en Tocqueville encontramos pre-dibujada nuestra hora. En realidad, también se citaba a Comte y a Macauly. Pero no se puede decir que Comte fuera en el camino del liberalismo. John Stuar Mill lo había dejado muy claro. De Macauly apenas se sabe nada más en la obra de Ortega ${ }^{81}$. En todo caso, si alguien había mostrado los problemas del doctrinarismo en la crisis de 1848, este había sido Tocqueville, y sólo desde esta figura intelectual se podía abrir camino un liberalismo nuevo. Tal cosa la vio el propio Díez del Corral cuando escribió su libro ${ }^{82}$.

Sin embargo, Ortega no se atrevió a dirigirse a Tocqueville de forma clara ${ }^{83}$. De hecho, cuando se propuso escribir un prólogo a su obra, mientras estaba en Argentina, sólo nos dejó un fragmento. En él sin embargo, Ortega comenzó diciendo que Tocqueville tenía páginas proféticas. Reconoció también que sus análisis sobre Inglaterra y Estados Unidos seguían vigentes. Sorprende sin embargo que, cada vez que hablara de Estados Unidos, Ortega no se inspirara en nuestro autor ni lo citase. Ortega era un lector suficientemente preciso como para saber que el problema central de Tocqueville era el de la democracia. En todo lo demás estaba equivocado. Para Ortega no cabía duda de que la democracia, como forma de Estado, implicaba una forma de autoritarismo. $Y$ de la peor, en la medida en que no podía existir sin una "maquinaria" específica caracterizada por la "centralización". En suma, democracia era otra forma de lo que "hoy solemos decir intervencionismo del Estado"84. Así, Ortega caminaba hacia el mundo al revés, en un 
momento, no hay que olvidarlo, que se combatía en todos sitios, un tiempo acerca del que, como ya había avisado en Argentina, en caso de guerra, él siempre estaría con Europa. Invirtiendo así el sentido completo de las cosas, vino a decir que la democracia era eso que se llamaba, con un vocablo bastante estúpido, "totalitarismo". En suma, Ortega ve a Tocqueville como el aristocrática francés indispuesto con la democracia desde el principio, y al que la experiencia americana no le había enseñado nada. Como en el mismo caso de Ortega, su libro tenía que ver con la Revolución francesa. Nada más. Que hubiera publicado su libro tan solo dos años después del regreso de su viaje, mostraba, en un escritor tan lento, que las verdaderas ideas venían ya de antes. Por lo demás, Tocqueville, señala Ortega, era un autor tímido, de esos que sólo expone sus verdaderas experiencias muy lentamente, que "retiene sus primeros movimientos" y los explicita tras larga reflexión. América sería sólo una ocasión que activaría sus verdaderas experiencias europeas y estas habian sido la ruina del Antiguo Régimen. Frente a ella, Tocqueville habría reaccionado identificando despotismo y democracia. Como vemos, Ortega estaba dispuesto a usar la autoridad de Tocqueville para indisponer a los espíritus contra la Revolución francesa, que "había machacado el antiguo régimen cuando estaba a punto de ser todo lo perfecto que una forma de sociedad y de gobierno puede ser" 85 .

Lo sorprendente de este comentario no reside en la alabanza sin par que Ortega dedica al Antiguo régimen. Tampoco que hubiera una especie de transferencia de melancolía del autor a su intérprete, lo que Ortega con razón se apresta a negar respecto a la mentalidad franca de Tocqueville. La experiencia personal del pensador francés, su problema personal, residiría en la existencia de un régimen nuevo en el que la nobleza familiar había desparecido, pero su problema era el futuro. Ortega lo sugiere, desde luego y comprende que una aristocracia no puede ser restaurada una vez que ha perdido su credibilidad. "La historia tiene de río no saber andar hacia atrás", recordó Ortega. Lo más sorprendente es que, una y otra vez, Ortega se niegue a apreciar la experiencia americana de Tocqueville. Nada de esa experiencia es relevante. Tocqueville fue un liberal, y su sentido de libertad se desprendía del "subsuelo de su fe cristiana". Su aspiración era crear "un armazón de instituciones políticas y de usos cotidianos que hagan posibles existencias libres". Esa era la meta de las sociedades modernas. Pero este, concluye Ortega, no era "un pensamiento político". Lo político era su realización de una constitución civil liberal. Y esto era justo lo que jamás se forjaría desde la "marea viva de la democracia que nada puede contener". La democracia, según Ortega, le parecía a Tocqueville una realidad que escapaba a todo poder humano. En suma, era un destino respecto al que sólo había dos opciones: reconciliarse con ella, o estrellarse ante ella. Cuando Ortega llegó a este punto, interrumpió el estudio, el ensayo, la introducción, el manuscrito.

Solo unas veces más mencionaría en su obra el nombre de Tocqueville. En 1949 siguió con el diagnóstico de Tocqueville: la democracia era el ascenso totalitario de las masas, y el francés había sido el primero en anunciarlo proféticamente, en el sentido de su propio libro La rebelión de las masas, en cuya segunda parte, Quien manda en el mundo citó. Sin embargo, algo más se movilizó aquí. Los males de Europa venían de que Inglaterra había intentado "con lamentable inoportunidad continentalizar su democracia"86. Tocqueville habría sido el primero en advertir este peligro. Era como una promesa. Tocqueville se debía "ir filtrando poco a poco en la mollera de la gente". Y sobre todo, su conclusión final, desencantada, que mostraba el final de las ilusiones de que la democracia implicara de algún modo la elección de los mejores, el escándalo que le producía el efecto que sobre la historia tenían los pequeños personajes" 87 . Esto era una nota en la meditación sobre Europa. Todavía en 1954, víspera de su muerte, Ortega repetía que en Tocqueville encontrábamos dibujada nuestra era. Pero ni una palabra más de en qué sentido. Ortega, siempre concluyó que el dilema era todavía o democracia o liberalismo.

Estas notas apresuradas muestran que Ortega sólo conocía la parte negativa de Tocqueville, y que jamás entró en su diagnóstico más interesante: que los Estados Unidos habian logrado la sintesis de liberalismo y democracia por su vida comunitaria activa, por su pluralidad de centros de poder, por su federalismo, por su virtud y por su implicación en la vida común, por su clara inclinación a detestar el paternalismo despótico, por su democracia como condición homogénea de sociedad que no iba a tolerar desigualdades aristocráticas. Claro que Tocqueville detectaba la demagogia como una forma de despotismo. Pero esto no se curaba con un aristocratismo intelectual intenso, sino con una mayor y más rigurosa comprensión de la libertad y de sus instituciones políticas liberales. 
Esto no era de recibo para Ortega. Por eso, en una nota anterior, tuvo que decir que Tocqueville, por defender el gobierno democrático como propio de la libertad políti$\mathrm{ca}$, en el sentido mismo que Montesquieu, "revelaría un radical desconocimiento de lo que es democracia a pesar de haber dedicado a su estudio entera su vida"88. Para Ortega, según confesó, la democracia es "per se enemiga de la libertad y por su propio peso [...] Ileva al absolutismo mayoritario"89. En suma, la doctrina aristotélica era certera: democracia era tiranía. Con ello, una obra que había sido traducida desde la mitad del siglo XIX ${ }^{90}$, y que había fundado el prestigio de la constitución americana en el pensamiento político español del federalismo y de la democracia, no podía ser volcada al presente ni recibida desde un punto de vista intelectual. Sin duda, hay que comprenderlo. Con Franco en el gobierno, el escenario Tocqueville era inimaginable.

Que América ofreciera la posibilidad de curar a Europa de sus males despóticos, puestos de manifiesto en la Revolución francesa, esto no podia aceptarlo Ortega. El mismo tabú demuestra hasta qué punto le resultaba imposible reconciliarse con Tocqueville. Primero, porque su liberalismo habría tenido que hacerse compatible con el sentido inequivoco de la democracia, lo que para Ortega era imposible. Segundo, porque tal cosa sólo se podía entender desde la centralidad de los Estados Unidos, el único país donde la democracia liberal de verdad funcionaba con suficiente fuerza como para derrotar a Hitler y su aspiración mundial de poder. Tal cosa le resultaba intragable a Ortega, que no podía entender que una sociedad neo-colonial, anclada en su primitivismo, pudiera dar lecciones a Europa. En realidad, Ortega no tuvo de Estados Unidos otra idea que la que aprendió en Hegel, sin sus expectativas de futuro. Al anclarse en estos dos insuperables prejuicios, el pensamiento de Ortega, en mi humilde opinión, resulta completamente incapaz de reconciliarse con la historia de Occidente $y$, en esta media, es contrario a su razón histórica, y por eso inútil para el presente. En realidad, entre Tocqueville y Burke, Ortega sin duda se quedó con este último. En este horizonte de referencia hay que entender el significado de la razón histórica.

\section{NOTAS}

1 Sánchez Cámara, que ha analizado el tema del liberalismo en Ortega, siempre se ve impelido a ofrecer la coletilla de que la critica de Ortega a la Restauración era "por lo demás exagerada y acaso injusta". Se debe ver, el por lo demás instructivo trabajo "Liberalismo y democracia en Ortega y Gasset", en el libro dirigido por Pedro Cerezo, Ortega en perspectiva, Instituto de España, Madrid, 2007, pp. 113-145. El párrafo reseñado es la p. 124. Sobre este problema se ha realizado una tesis en Buenos Aires que no ha podido ser consultada. Enrique Aguilar, Sobre el liberalismo, Buenos Aires, 1986.

2 OC, $X, 126$. Por eso Cerezo tiene razón al proponer que lo caracteristico de este periodo se puede describir asi: "un Estado fuerte y educador, activo y beligerante, baluarte de las libertades civiles y los nuevos derechos sociales". En su trabajo "Ortega y la regeneración del liberalismo: tres navegaciones y un naufragio", en F. H. Llano y A. Castro, Meditaciones sobre Ortega y Gasset, Editorial Tébar, Madrid, 2005, pp. 629 y ss.

3 Por eso no parece que este sea un liberalismo de la razón vital, sino uno que asume determinadas condiciones de posibilidad en una actitud vital, más allá de una desnuda actitud normativa basada en la idea moral. En este sentido matizaría la afirmación de Sánchez Cámara: "La segunda navegación, orientada hacia un liberalismo de la vitalidad, se sustentaba en su nueva metafísica de la razón vital" (Sánchez Cámara, ob. cit., p. 125). En 1914 no se puede hablar todavía de una "metafísica de la razón vital". La tesis de Cerezo es más matizada:
Aceptado: 10 de octubre de 2010

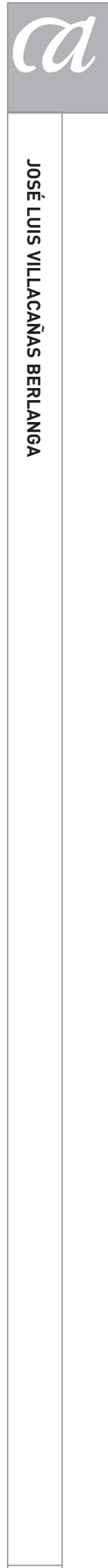


"El agente de regeneración no viene ahora tanto de la normatividad ética, sino de la realidad vital". Cf. Cerezo, ob. cit., p. 635. Creo que es así.

4 Las he intentado abordar en mi edición de las Meditaciones del Quijote, Biblioteca Nueva, Madrid, 2002.

5 Esta sensación ya la manifiesta Ortega en su viaje primero a Argentina, donde encuentra su camino hacia la filosofía sistemática. He analizado este punto de su pensamiento en "Ortega y el monopolio de la modernidad", en Iberian and Latin American Studies, vol. 13, n. ${ }^{\text {s }}$ 2-3, 2007, pp. 169-185.

6 Lo he analizado en Kant desde dentro, Isegoría.

7 Por tanto, es en este texto donde se debería cifrar la tercera posición del liberalismo en Ortega, para Cerezo, que ve este liberalismo de Ortega en la democracia liberal, en la sensibilidad radical liberal contraria a la estatolatría. Cf. Cerezo, ob. cit., p. 642. En la descripción que hace Sánchez Cámara de las posiciones de Aguilar, ve el tercer liberalismo en Meditación de Europa y Del Imperio romano. Pero el mismo Ortega reconoció que el primer escrito debe ponerse en relación con los textos complementarios de $L a$ Rebelión de las masas.

$8 \mathrm{He}$ analizado este momento en $L a$ cuarta pregunta. En el congreso Ortega presente y futuro, Madrid, 2008.

9 "La pavorosa homogeneidad de situaciones en que va cayendo todo el Occidente". La Rebelión de las masas, O.C., IV, p. 116 (en adelante, RM, IV, y página).

10 La Rebelión de las masas, 0.C., IV, p. 113.

11 He desarrollado el pensamiento posterior de Ortega sobre Europa en mi ensayo.

12 RM, IV, ob. cit., p. 117.
13 Geoestrategia que está muy presente en el subsuelo del trabajo de Ortega y que se ve en determinados comentarios que se colocan aquí y allá, de forma medida. Así, en RM, IV, ob. cit., p. 119 se dice: "La ocasión que lleve súbitamente a término el proceso [de imponer un Estado general europeo] puede ser cualquiera: por ejemplo, la coleta de un chino que asome por los Urales, o bien una sacudida del gran magma islámico". En el fondo, esto le hace decir a veces cosas que parecen cercanas al Carl Schmitt del Nomos de la Tierra. Así, en el "Epílogo para ingleses", y sobre todo en este apéndice que es "En cuanto al pacificismo", Ortega dice: "Considerada en lo que al derecho importa, la historia es ante todo, el cambio en el reparto del poder sobre la tierra". Su visión de la Sociedad de Naciones es claramente pro alemana y coincide con la de Schmitt: "el fracaso de la Sociedad de Naciones, gigantesco aparato construido para adminsitrar el statu quo". RM, IV, ob. cit., p. 293.

14 RM, IV, ob. cit., pp. 120-121: "L'Europe n'est qu'une nation composée de plusieurs", y "le grande famille continentale".

15 RM, IV, ob. cit., p. 285.

16 RM, IV, ob. cit., p. 120.

17 Cf. RM, IV, ob. cit., p. 122, nota. Ortega curiosamente hacía un Ranke un aprendiz de Guizot.

18 RM, IV, ob. cit., p. 121.

19 Alli, Ortega conoce de forma completa la división de las esferas de acción y hace de ella la nueva barbarie, que entrega cientificidad, pero ninguna cultura. Misión de la Universidad, OC, IV, ob. cit., p. 322. Aquí estableció el diagnóstico weberiano, según el cual la especialización había roto al hombre europeo. Entonces lo puso en relación con la destrucción de
Europa tal y como había existido. "el desmoronamiento de nuestra Europa, visible hoy, es el resultado de la invisible fragmentaación que progresivamente ha padecido el hombre europeo". Entonces citó el capítulo de La rebelion de las masas que lleva por título "La barbarie del especialismo", IV, 215 y ss. Este momento todavía hacia referencia a la totalidad carismática de la vida, que Ortega desarrolla por los años 30. En realidad, se trataba de las ideas que a través de la cultura pueden dotar al europeo de totalidad. Para ello debía anclar en la potencia auténtica de la vida, en "toda la vida nueva". IV, 327. Todavía este periodo, ordenado alrededor de la razon vital, no rompe con la filosofía de la cultura, sino que la renueva. "Cultura es el sistema de ideas vivas que cada tiempo posee: mejor, el sistema de ideas desde las cuales el tiempo vive". IV, 341. En esta medida, en tanto que sistema, propone jerarquía de los valores, con la que contrarrestar la igual especialización. Aunque ya se propone una idea biográfica de vida, la cultura es lo dominante y todavía no se ha dado el paso a la idea histórica. Así dice Ortega: "Pero siempre hay un sistema de ideas vivas que representa el nivel superior del tiempo, un sistema que es plenamente actual. Este sistema es la cultura". IV, 342. Estas ideas son "caminos por la selva de la existencia", y en este sentido ofrecen las interpretaciones básicas con las que encarar el tiempo. Sin embargo, como sucedía con el tono de Rebelión de las Masas, Ortega muestra sus tonos pesimistas, al hablar de una época de "terrible incultura". Por eso la misión de la Universidad pasa por recuperar "la plena cultura del tiempo". Sólo así, con una "nueva 
integración del saber", puede esperar Europa una salvación. IV, 347. Esta oferta carismática, implica una idea de totalidad. Esta es la misión de la universidad: especializarse "en la construcción de una totalidad".

20 RM, IV, ob. cit., p.121.

21 RM, IV, ob. cit., p. 128. Lo que da pie a sus reflexiones sobre el imperio romano, con su vulgarización del latín homogéneo, y sus pautas de vida completamente uniformes, que ocuparan sus dias de inmediato regreso a España.

22 RM, IV, ob. cit., p. 123.

23 Sus Ilamadas contra el viejo liberalismo son muy claras: "No pretendo que el viejo liberalismo sea una idea plenamente razonable. ¡Cómo va a serlo si es viejo y si es ismo!" RM, IV, ob. cit., p. 122. Desde luego no podía ser individualista, que le parecía propio del siglo XVIII. RM, IV, ob. cit., p. 125.

24 RM, IV, ob. cit., p. 118, nota 1.

25 RM, IV, ob. cit., p. 117.

26 RM, IV, ob. cit., p. 116.

27 "El liberalismo individualista pertenece a la flora del siglo XVIII, inspira en parte la legislación de la Revolución Francesa, pero muere con ella". RM, IV, ob. cit., p. 125.

28 La frase es fuerte y deseo repetirla: "Mas cuando se ha visto con claridad lo que en [...] el hecho colectivo [...] hay por un lado de benéfico, pero, por otro, de terrible, de pavoroso, sólo puede adherir uno a un liberalismo de estilo radicalmente nuevo, menos ingenuo y de más diestra beligerancia, un liberalismo que está germinando ya, próximo a florecer, en la línea misma del horizonte". RM, IV, ob. cit., p. 127.

29 "Eludo precisar a qué gremio pertenecian los profetas. Baste decir que en la fauna humana representan la especie más opuesta al político. Siempre será este el que deba go- bernar, y no el profeta. Pero importa mucho a los destinos humanos que el político oiga siempre lo que el profeta grita o insinúa. Todas las grandes épocas de la historia han nacido de la sutil colaboración entre esos dos tipos de hombres". RM, OC, IV, 291.

30 RM, IV, ob. cit., p. 130.

31 RM, IV, ob. cit., p. 131.

32 RM, IV, ob. cit., p. 132.

33 RM, IV, ob. cit., p. 134.

34 RM, IV, ob. cit., p. 133.

35 RM, IV, ob. cit., p. 285.

36 RM, IV, ob. cit., p. 296.

37 RM, IV, ob. cit., p. 298.

38 RM, IV, 307: "Alberto Einstein usufructúa una ignorancia radical sobre lo que ha pasado en España ahora, hace siglos y siempre. El espíritu que le lleva a esta insolente intervención es el mismo que desde hace mucho tiempo viene causando el desprestigio universal del hombre intelectual, el cual, a su vez, hace que vaya el mundo a la deriva, falto de pouvoir spirituel".

39 RM, IV, ob. cit., p. 300.

40 En relación con el argumento que hemos desarrollado en una nota anterior, Ortega expone esta contraposición entre la misión verdadera de la universidad y el poder de la prensa en las páginas finales de la Misión de la Universidad. "Hoy no existe en la vida pública más poder espiritual que la Prensa". Desde luego, la Iglesia ha abandonado el presente porque ha abandonado la prensa. El comentario es sabroso. No sólo por la capacidad mostrada por la Iglesia a la hora de vincularse a la Prensa, sino por la síntesis de universidad y de prensa que al parecer ha sido el resultado del proceso intelectual español. Ahora bien, para Ortega, como para Weber, en la jerarquía de las realidades espirituales el periodismo ocupa el rango inferior. IV, 352. Pues los periodistas no son sino pseudointelectuales chafados llenos de resentimiento y de odio hacia el verdadero espíritu.

41 RM, IV, ob. cit., p. 300.

42 RM, IV, ob. cit., p. 300.

43 RM, IV, ob. cit., p. 284.

$44 \mathrm{El}$ análisis de la función de la prensa por parte de Ortega es elemental pero efectivo: la prensa aumenta el desconocimiento entre los países. Hay una extrema proximidad dinámica y una opinión incongruente: esto significa que el desconocimiento tiene efectos políticos. Esto permitía a las opiniones públicas de un país actuar en otro, pero desde el desconocimiento, sin "la verdad de lo vivido". RM, IV, ob. cit., pp. 303-304.

45 RM, IV, ob. cit., p. 299.

46 Misión de la Universidad, OC, IV, 352.

47 En todo caso, el diagnóstico de Ortega ha fracasado. La Universidad ahora está al servicio bochornoso de la prensa y es ésta la que define los prestigios, la excelencia y la funcionalidad de los estudios.

48 RM, IV, ob. cit., p. 295.

49 RM, IV, ob. cit., p. 298.

50 RM, IV, ob. cit., p. 309.

51 RM, IV, ob. cit., p. 300.

$52 \mathrm{El}$ concepto aparece en RM, IV, ob. cit., p. 304.

53 RM, IV, ob. cit., pp. 104-305.

54 RM, IV, ob. cit., p. 306

55 Desde luego, Ortega llamaba la atención acerca de cómo en Inglaterra se abortaba el frente popular que se defendia en España. "Esa incongruente conducta, esa duplicidad de la opinión laborista, sólo irritación puede inspirar fuera de Inglaterra". RM, IV, ob. cit., p. 307. Desde luego, jamás se para a pensar en el problema importante: el enemigo del laborismo inglés era Hitler y el frente popular español podía pararlo. Esto no quiere decir que el laborismo inglés se 
quisiese arrastrar a una tragedia. En este sentido, la responsabilidad del pueblo español era suya. Nadie se veía obligado a secundar su drama. Pero una vez éste desencadenado, era evidente hacia qué posición debía dirigirse la izquierda inglesa. En esto, Inglaterra se comportaba como una potencia bien informada. Ortega no quiere oír hablar de esto.

56 RM, IV, ob. cit., p. 306.

57 RM, IV, ob. cit., p. 305.

58 RM, IV, ob. cit., p. 305.

59 RM, IV, ob. cit., p. 309.

60 "Leyendo el 'Adolfo',libro de amor", El espectador, OC, II, pp. 25-28.

61 "Para la cultura del amor", El espectador, OC, II, pp. 140-145.

62 Una en "La interpretación bélica de la historia", OC, II, p. 529. Luego en el prólogo de la Historia de la civilización europea, cf. la edición de Alianza Editorial, Madrid, 1966, pp. 7-10.

63 No es de desdeñar la idea de que Ortega pensara que sólo el principio monárquico liberal doctrinario, ejercido por un pretendiente como Don Juan fuera la solución para España. Tampoco es un azar que marche a Portugal pronto.

64 OC, XII, p. 293, para afirmar que en Europa sólo queda desnuda la fuerza de la facticidad, no la fuerza de la normatividad. "Hechos que son fuerza" y no "cosas que son derechos". La misma referencia, en el fondo, es la que deja caer en "Cómo muere una creencia", en el lejano 1954. OC, IX, 711. Luego está la aparición de V, 253 y ss. y las propias de la Rebelion de las masas.

65 Luis Díez del Corral, El liberalismo doctrinario, CEC, Madrid, 1984.

66 RM, OC, IV, 122 y siguientes. Sin duda cita entonces la frase de Historia de la civilización europea: "La coexistencia y el combate de principios diversos".

67 RM, OC, IV, 124, nota 1.

68 Esto es lo que en el fondo ve de positivo en el libro de Spencer, El individuo contra el Estado. RM, OC, IV, p. 126.

69 RM, OC, IV, p. 125.

70 RM, OC, IV, p. 134.

$71 \mathrm{RM}, \mathrm{OC}, \mathrm{IV}$, p. 126, nota 1.

72 RM, OC, IV, p. 122.

73 RM, OC, IV, p. 128.

74 "El fracaso de la razón física deja vía libre para la razón vital e histórica", OC, VI, p. 23.

75 Historia como sistema, OC, VI, p. 50. 76 RM, OC, IV, p. 136.
77 RM, OC, IV, p. 134: "Los problemas humanos [...] son problemas de máxima concreción, porque son históricos. $Y$ el único método de pensamiento que proporciona alguna probabilidad de acierto en su manipulación es la 'razón histórica'".

78 RM, OC, IV, p. 137.

79 RM, OC, IV, p. 138.

80 OC, IV, pp. 357-378.

81 IV, 127 y 133 que se repite en IX, 696. Luego está el pasaje de V, 221.

82 El liberalismo doctrinario, ob. cit., 440 y ss.

83 IV, 127, V, 221, 248n, y IX, 250n, 266n. Y 327.331.

84 Toqueville y su tiempo, IX, 328.

85 IX, 330.

86 IX, 266.

87 IX, 266.

88 IX, p. 250.

89 IX, 250 nota.

90 Se tradujo, en De la democracia en América:con un examen dela democracia en los Estados-UnidosyenSuiza, por Alejandro de Tocqueville, seguido de un estudio sobreel carácter democrático de la sociedad española porE. Chao Publicación:Madrid:[s.n.], 1854(Imprenta de D. Jose Trujillo). 